metallic compounds. $\pi$-Nucleophiles of widely varying structure can, therefore, be compared with respect to the same electrophiles.

Acknowledgment. We thank Dr. S. Pask and Prof. O. Nuyken for suggesting the kinetic methods used in this work, Prof. M. Marxen and Dipl. Ing. H.-P. Schmidt (Fachhochschule Lübeck) for help during the construction of the work station and Ute Grabis and Monika Rubow for experimental assistance. Financial support by the Deutsche Forschungsgemeinschaft, Stiftung Volkswagenwerk (Kekulê grant to C.S.) and the Fonds der Chemischen Industrie is gratefully acknowledged.

Supplementary Material Available: Tables with concentrations and rate constants at different temperatures for the reactions of 2-X, $\mathbf{Y} \cdot \mathrm{BCl}_{4}{ }^{-}$with 3 (8 pages). Ordering information is given on any current masthead page.

\title{
Kinetics of the Reactions of the p-Methoxy-Substituted Benzhydryl Cation with Various Alkenes and 1,3-Dienes
}

\author{
Herbert Mayr, ${ }^{*}$ Reinhard Schneider, Bernhard Irrgang, and Christian Schade \\ Contribution from the Institut für Chemie der Medizinischen Universität zu Lübeck, Ratzeburger \\ Allee 160, D-2400 Lübeck 1, Federal Republic of Germany. Received October 25, 1989
}

\begin{abstract}
The kinetic method described in the preceding article has been used to determine the rate constants for the reaction of $\left(p-\mathrm{CH}_{3} \mathrm{OC}_{6} \mathrm{H}_{4}\right)\left(\mathrm{C}_{6} \mathrm{H}_{5}\right) \mathrm{CH}^{+} \mathrm{BCl}_{4}^{-}$with 30 alkenes and 1,3-dienes in dichloromethane at -80 to $-30^{\circ} \mathrm{C}$. The second-order rate constants, which reflect the rate of attack of $\left(p-\mathrm{CH}_{3} \mathrm{OC}_{6} \mathrm{H}_{4}\right)\left(\mathrm{C}_{6} \mathrm{H}_{5}\right) \mathrm{CH}^{+}$at these $\pi$-systems strongly depend on the electron-releasing ability of the substituents at the developing carbenium center $\left(\mathrm{H}_{2} \mathrm{C}=\mathrm{C}\left(\mathrm{CH}_{3}\right) \mathrm{R}: \mathrm{R}=\mathrm{H}, 9.39 \times 10^{-4} ; \mathrm{R}\right.$ $=$ vinyl, 15.6; $\mathrm{R}=\mathrm{CH}_{3}, 23.3 ; \mathrm{R}=\mathrm{Ph}, 1450 ; \mathrm{R}=$ cyclopropyl, $5650 \mathrm{~L} \mathrm{~mol}^{-1} \mathrm{~s}^{-1}$ at $\left.-70{ }^{\circ} \mathrm{C}\right)$. The steric effects of substituents at this position are of minor importance $\left(\mathrm{H}_{2} \mathrm{C}=\mathrm{C}\left(\mathrm{CH}_{3}\right) \mathrm{R}: \mathrm{R}=\mathrm{Me}, 23.3 ; \mathrm{R}=\mathrm{Et}, 18.4 ; \mathrm{R}=i-\mathrm{Pr}, 6.08 ; \mathrm{R}=t-\mathrm{Bu}, 1.21 \mathrm{~L}\right.$ $\mathrm{mol}^{-1} \mathrm{~s}^{-1}$ at $-70^{\circ} \mathrm{C}$ ). Methyl groups at the electrophilically attacked vinylic position usually lower $\Delta H^{*}$ and $\Delta S^{*}$, while a uniform effect on the rate constants is not found.
\end{abstract}

In the preceding article we have reported that colorless, covalent products are formed when 2-methyl-1-pentene is added to the colored ionic solutions of several diarylcarbenium tetrachloroborates in $\mathrm{CH}_{2} \mathrm{Cl}_{2},{ }^{1}$ and we have shown that the rate of disappearance of the diarylcarbenium ions, which can be measured photometrically and conductimetrically, equals the rate of attack of the carbenium ions at the alkenes. We report now on the

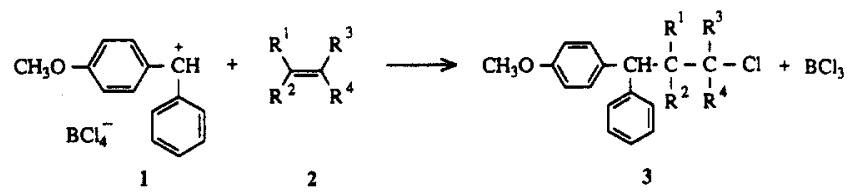

relationship between the structure and reactivity of alkenes and 1,3-dienes employing the p-methoxy-substituted benzhydryl cation 1 as the reference electrophile. This is the first report on absolute rate constants of various vinyl derivatives toward carbenium ions since Dorfman's pioneering work on the reactivity of radiolytically generated benzyl and benzhydryl cations toward some unsaturated hydrocarbons. ${ }^{2}$ A smaller set of data on relative reactivities of alkenes has previously been published by us. ${ }^{3}$

\section{Experimental Section}

The kinetic method has been described in the preceding article, ${ }^{1}$ and the results of the individual kinetic experiments are given in the supplementary material. All reaction products obtained from $1 \cdot \mathrm{BCl}_{4}^{-}$with 2 were characterized by ${ }^{1} \mathrm{H}$ NMR and/or ${ }^{13} \mathrm{C}$ NMR spectroscopy. Spectral and other physical data of the reaction products are documented in ref 4 .

\section{Reaction Products.}

The combination of $1 \cdot \mathrm{BCl}_{4}^{-}$with compounds $2 \mathrm{a}-\mathrm{dd}$ yields $1: 1$ products in almost quantitative yields, as previously described for analogous reactions of other benzhydryl chlorides. ${ }^{3,5}$ For un-

(1) Mayr, H.; Schneider, R.; Schade, C.; Bartl, J.; Bederke, R., preceding paper in this issue.

(2) Wang, J.; Dorfman, L. M. Macromolecules 1980, 13, 63

(3) (a) Mayr, H.; Pock, R. Chem. Ber. 1986, 119, 2473. (b) Pock, R.; Mayr, H. Chem. Ber. 1986, /19, 2497. symmetrical alkenes, the electrophilic attack of 1 takes place regioselectively to give the most stabilized carbenium ion, ${ }^{6}$ and the adducts 3 are usually the exclusive or the predominant products. When secondary alkyl cations are involved as intermediates, 1,2-hydrogen shifts often cannot be avoided, and in the reactions of $1 \cdot \mathrm{BCl}_{4}{ }^{-}$with $\mathbf{2 a - d}$, the main products $3 \mathrm{a}-\mathbf{d}$ are accompanied by some rearranged material. The stereoselectivities of the addition reactions with the $E, Z$-isomeric 2 -butenes $2 \mathbf{b}, \mathbf{c}$ and 1-phenylpropenes $2 s, t$ are comparable to the results reported for the analogous reactions of diphenylmethyl chloride and di$p$-tolylmethyl chloride. ${ }^{7}$ By analogy with an earlier report, ${ }^{8}$ norbornene $2 \mathrm{e}$ reacts with complete Wagner-Meerwein rearrangement to give a 7 -(diarylmethyl)-2-chloronorbornane, and 2-cyclopropylpropene 2dd undergoes the well-known cyclopropylcarbinyl/homoallyl rearrangement with exclusive formation of 1,1-diaryl-6-chloro-3-methyl-3-hexene. ${ }^{3 b}$

The ordinary addition products 3 are accompanied by the indans 4 and 5 , when $1 \cdot \mathrm{BCl}_{4}{ }^{-}$is combined with the alkenes $21-\mathrm{p}, \mathrm{s}, \mathrm{t}$. While 4 and 5 are formed in approximately equal amounts in all cases, the ratio $3 /(4+5)$ strongly depends upon the reaction conditions as described for the reaction of bis(p-methoxyphenyl)carbenium tetrachloroborate with trimethylethylene. ${ }^{1}$ The alkenes $2 \mathrm{~m}$ and $2 p$ react with exclusive or predominant formation of the indans 4 and 5 ( $\left(\mathrm{gem}\right.$-dialkyl effect $^{9}$ ).

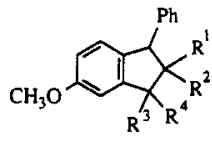

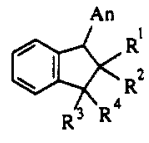

(4) (a) Schneider, R. Dissertation, Universität Erlangen-Nürnberg, 1987. (b) Schade, C. Dissertation, Medizinische Universität zu Lübeck, 1988. (c) Irrgang, B. Dissertation, Medizinische Universität zu Lübeck, 1990

(5) Mayr, H.; Striepe, W. J. Org. Chem. 1983, 48, 1159.

(6) Unsymmetrical $\pi$-systems are attacked at the left $\mathrm{sp}^{2}$ carbon of the formula drawings in Table I.

(7) Pock, R.; Mayr, H.; Rubow, M.; Wilhelm, E. J. Am. Chem. Soc. 1986, $108,7767$.

(8) Pock, R.; Klein, H.; Mayr, H. Chem. Ber, 1986, 119, 929.

(9) Review: Capon, B.; McManus, S. P. Neighboring Group Participation; Plenum Press: New York, 1976, Vol. 1, p 58. 
While indan formation is not observed from terminal alkenes under these reaction conditions, the olefins $2 \mathbf{h}$ and $2 \mathbf{i}$ yield the tetrahydronaphthalenes 6 and 7 in addition to the regular adducts 3 and the rearrangement products 8 , indicating that cyclizations with formation of six-membered rings are favored over formation of five-membered rings. ${ }^{10}$

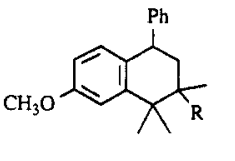

6

$R=H:(6-8) h$;

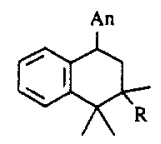

7

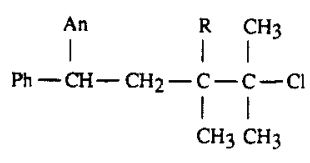

Mixtures (1:1) of 1,2- and 1,4-addition products are obtained in the reaction of $1 \cdot \mathrm{BCl}_{4}^{-}$with $2 \mathrm{u}$ and $2 \mathrm{v}$. While the $1,2-$ and 1,4-addition products obtained from $2 \mathbf{u}$ do not isomerize under the reaction conditions (kinetic control), the product mixture obtained from $2 \mathrm{v}$ appears to be thermodynamically controlled. With all other dienes $(2 \mathrm{w}-\mathrm{cc})$ the predominant formation of 1,4-adducts ( $>90 \%)$ is observed. Since the 1,4-adducts obtained from $2 y-c c$ incorporate three chiral centers, mixtures of diastereoisomers are produced, which show complex ${ }^{13} \mathrm{C}$ NMR spectra. ${ }^{4 c}$

\section{Kinetic Investigations}

Second-order kinetics were found for the reactions of $1 \cdot \mathrm{BCl}_{4}{ }^{-}$ with most nucleophiles listed in Table $\mathrm{I}$. The reactions of $1 \cdot \mathrm{BCl}_{4}{ }^{-}$ with $2 \mathbf{a}$ and $\mathbf{2 b}$ did not follow the second-order rate law, and the $k_{2}$ values derived from the initial slopes of the second-order plots were greater than those calculated at a higher degree of conversion. Since the electrophilic attack at these alkenes yields secondary carbenium ions, the curvature of the graphs was explained by the reversibility of the addition step, which gains importance as the $\mathrm{BCl}_{4}^{-}$concentration decreases toward the end of the conversion. As discussed in the previous article, ${ }^{1}$ this complication can be overcome by studying the reactions in the presence of $\mathrm{PhCH}_{2} \mathrm{NEt}_{3}{ }^{+} \cdot \mathrm{BCl}_{4}^{-}\left(\sim 10^{-2} \mathrm{~mol} \mathrm{~L}^{-1}\right)$. Linear second-order plots to more than $80 \%$ conversion are now observed, and since the $k_{2}$ values derived from these plots are identical with those observed for the reaction of $1 . \mathrm{SnCl}_{5}^{-}$with $2 \mathbf{b}$ in the presence of $\mathrm{PhCH}_{2} \mathrm{NEt}_{3}{ }^{+} \cdot \mathrm{SnCl}_{5}{ }^{-}$, we conclude that the observed reaction rates are identical with the rates of attack of the carbenium ion 1 at these alkenes.

Consequently, all reactions of $1 \cdot \mathrm{BCl}_{4}{ }^{-}$, which proceed through secondary carbenium ions or which involve alkenes with a high polymerization tendency (e.g. 2r) have been investigated in the presence of $\mathrm{PhCH}_{2} \mathrm{NEt}_{3}{ }^{+} \cdot \mathrm{BCl}_{4}{ }^{-}\left(\sim 10^{-2} \mathrm{~mol} \mathrm{~L}^{-1}\right)$. Since the reaction of $1 \cdot \mathrm{BCl}_{4}{ }^{-}$with tetramethylethylene (2p) gave the indans 4 and 5 almost exclusively, variation of $\left[\mathrm{BCl}_{4}^{-}\right]$did not influence the reaction rate. There is indirect evidence, however, that the attack of 1 at the tetrasubstituted ethylene $2 p$ is a reversible process, ${ }^{11}$ and the $k_{2}$ value given in Table I has to be considered as a lower limit for the rate of attack of $\mathbf{1}$ at $\mathbf{2 p}$.

Usually, no complications arise when $\mathrm{HBCl}_{4}$ is generated during the reactions along with the cyclized products $4-7$, as $\mathrm{HBCl}_{4}$ reacts very slowly with the alkenes. Since $\mathrm{HBCl}_{4}$ only dissociates to a very small extent in $\mathrm{CH}_{2} \mathrm{Cl}_{2}$, this side reaction does not interfere with measurements obtained by the conductimetric method.

\section{Structure-Reactivity Relationships}

Activation Entropies. Table I shows that enthalpic and entropic effects are responsible for the variations of the $k_{2}$ values, which cover a range of $6 \times 10^{6}$. Some regularities of the $\Delta S^{*}$ values

(10) As these cyclizations can either be classified as exo-trig or endo-trig processes, Baldwin's rules do not allow a prediction: Baldwin, J. E. J. Chem. Soc., Chem. Commun. 1976, 734.

(ii) Schneider, R.; Mayr, H. Unpublished results.

(12) (a) Chwang, W. K.; Nowlan, V. J.; Tidwell, T. T. J. Am. Chem. Soc. 1977, 99, 7233. (b) Knittel, P.; Tidwell, T. T. J. Am. Chem. Soc. 1977, 99, 3408. (c) Oyama, K.; Tidwell, T. T. J. Am. Chem. Soc. 1976, 98, 947. (d) Chwang, W. K.; Knittel, P.; Koshy, K. M.; Tidwell, T. T. J. Am. Chem. Soc 1977, 99, 3395. (e) Jensen, J. L.; Uaprasert, V. J. Org. Chem. 1976, 41, 649. are noticeable: All 1,1-dialkylated ethylenes possess $\Delta S^{*}$ values of $(-117 \pm 5) \mathrm{J} \mathrm{mol}^{-1} \mathrm{~K}^{-1}$, and in all classes of compounds $\Delta S^{*}$ becomes more negative when an alkyl group is introduced at the electrophilically attacked carbon. The effect of a trans substituent is generally greater than that of a cis substituent (Table II).

$\alpha$-Substituent Effects. The predominant role $\alpha$-substituents, i.e., substituents at the developing carbenium center is manifested by the fact that the $k_{2}$ values of Table I allow the alkyl-substituted ethylenes to be divided into two sets: Compounds 2a-d, which yield secondary carbenium ions, and compounds $2 \mathbf{f}-\mathbf{p}$, which yield tertiary carbenium ions. If the sterically shielded compound $\mathbf{2 m}$ is omitted, norbornene (2e) is located in between these two groups.

Comparison of compounds $\mathbf{2} \mathbf{f}-\mathbf{k}$ shows that branching of an $\alpha$-alkyl group has a moderate influence on the addition rate constants. The reduction of reactivity created by branching in the allylic position (series 1) indicates the predominance of the steric effect, while the slight reactivity increase caused by branching in the homoallylic position (series 2) can be attributed to hyperconjugative stabilization of the generated carbenium ion.

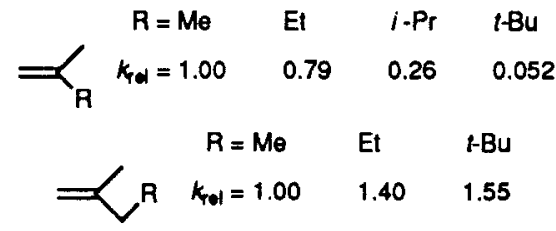

The modest magnitude of the effect in both series suggests, however, that steric effects of $\alpha$-substituents can be neglected in the following discussion, when substituents with different electronic properties are compared.

Replacement of hydrogen by a methyl group at the developing carbenium center increases the reactivity by a factor of 25000 (series $3, \mathrm{R}=\mathrm{H}$ vs $\mathrm{CH}_{3}$ ) and an acceleration by 5 orders of magnitude is observed when a vinylic hydrogen in 2-butene $(\mathbf{2 l} / \mathbf{2 b}$, $21 / 2 c)$ or cyclopentene $(\mathbf{2 n} / \mathbf{2 d})$ is substituted by methyl. The relative activating effects of methyl and vinyl groups are opposite at tertiary (series 3 ) and at secondary positions (series 4 ): Whereas butadiene ( $2 u$ ) is 21 times more reactive than propene (2a), the reactivity of isoprene $(2 w)$ is only 0.67 times that of isobutene (2f). A phenyl group activates considerably better than methyl

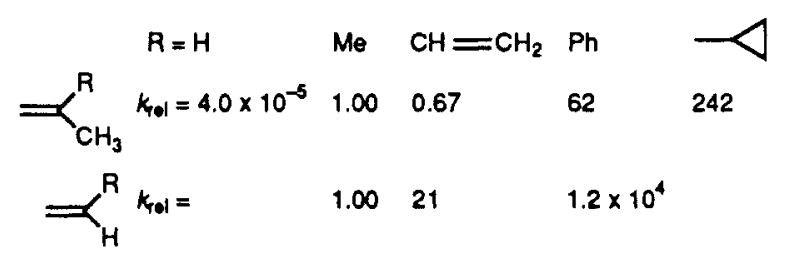

when located at a secondary center $\left(1.2 \times 10^{4}\right)$ but only somewhat better than methyl when located at a tertiary center (62). This trend may be explained by the different electron demand..$^{13}$ The activating effect of cyclopropyl is greater than that of vinyl and phenyl, further evidence for the unique electron-releasing ability of the cyclopropyl group. ${ }^{14}$

$\beta$-Substituent Effects. Methyl groups at the initially attacked vinylic position do not have a uniform effect on the rate constants. Activating as well as deactivating effects are observed (Table II). When we disregard cis- $\beta$-methylstyrene (2t), the low reactivity of which may be explained by the nonplanarity of the $\pi$-system, we realize that methyl groups at the attacked vinylic position generally reduce $\Delta S^{*}$ as well as $\Delta H^{*}$. While the reduction of $\Delta H^{*}$ is relatively small for the 2-butenes, big effects on $\Delta H^{*}$ are found in the comparisons $21 / 2 f$ and $2 y / 2 v$ (Table II).

PMO theory may be used to explain the enthalpic effects. Since the second-order perturbation energy $\left(\Delta E_{1}\right.$ and $\Delta E_{2}$, Figure 1)

(13) Larsen, J. W.; Bouis, P. A.; Riddle, C. A. J. Org. Chem. 1980, 45, 4969 and references cited therein

(14) (a) Review: Richey, H. G., Jr. In Carbonium Ions; Olah, G. A.; Schleyer, P. v. R., Eds.; Wiley-Interscience: New York, 1972; Vol. III, Chapter 25. (b) Olah, G. A.; Surya Prakash, G. K.; Liang, G. J. Org. Chem. $1977,42,2666$ and references cited therein. 
Table I. Rate Constants $\left(-70.0^{\circ} \mathrm{C}\right)$ and Activation Parameters for the Reactions of $p$-Methoxydiphenylcarbenium Tetrachloroborate $\left(1 \cdot \mathrm{BCl}_{4}{ }^{-}\right)$ with Various Alkenes and Dienes in Dichloromethane

\begin{tabular}{|c|c|c|c|c|c|}
\hline & & $\begin{array}{c}k_{2}\left(-70^{\circ} \mathrm{C}\right)^{a, b} \\
\mathrm{~L} \mathrm{~mol}^{-1} \mathrm{~s}^{-1}\end{array}$ & $\begin{array}{c}\Delta H^{*}, \\
\mathrm{~kJ} \mathrm{~mol}^{-1}\end{array}$ & $\begin{array}{c}\Delta S^{*}, \\
\mathrm{~J} \mathrm{~mol}{ }^{-1} \mathrm{~K}^{-1}\end{array}$ & $\begin{array}{c}\left.k_{\mathrm{H}_{3} \mathrm{O}^{+}}\left(25^{\circ} \mathrm{C}\right)\right)^{c} \\
\mathrm{~L} \mathrm{~mol}^{-1} \mathrm{~s}^{-1}\end{array}$ \\
\hline \multicolumn{6}{|c|}{ Mono- and 1,2-Dialkylated Ethylenes } \\
\hline & 2a & $9.39 \times 10^{-4}$ & $32.6 \pm 0.2$ & $-139 \pm 1$ & $2.38 \times 10^{-9}(\operatorname{ref} 12 \mathrm{a})$ \\
\hline & $\mathbf{2 b}$ & $1.26 \times 10^{-3}$ & $29.9 \pm 0.5$ & $-150 \pm 2$ & $3.51 \times 10^{-8}(\operatorname{ref} 12 \mathrm{~b})$ \\
\hline & $2 c$ & $1.01 \times 10^{-3}$ & $31.4 \pm 0.4$ & $-145 \pm 2$ & $8.32 \times 10^{-8}($ ref $12 b)$ \\
\hline & 2d & $7.0 \times 10^{-3}$ & & & \\
\hline & $2 \mathbf{e}$ & $7.82 \times 10^{-1}$ & $23.9 \pm 0.3$ & $-126 \pm 1$ & $3.41 \times 10^{-5}(\operatorname{ref} 12 \mathrm{a})$ \\
\hline \multicolumn{6}{|c|}{ 1,1-Dialkylated Ethylenes } \\
\hline & $2 f$ & $2.33 \times 10^{1}$ & $21.1 \pm 0.4$ & $-112 \pm 2$ & $3.71 \times 10^{-4}($ ref $12 a)$ \\
\hline & $2 g$ & $1.84 \times 10^{1}$ & $21.4 \pm 0.2$ & $-112 \pm 1$ & $5.22 \times 10^{-4}(\operatorname{ref} 12 c)$ \\
\hline & $2 \mathrm{~h}$ & 6.08 & & & \\
\hline & $\mathbf{2 i}$ & 1.21 & $24.4 \pm 0.5$ & $-120 \pm 3$ & $2.04 \times 10^{-4}($ ref $12 c)$ \\
\hline & $2 \mathrm{j}^{d}$ & $2.58 \times 10^{1}$ & 19.5 & -119 & \\
\hline & 2k & $2.86 \times 10^{1}$ & $18.6 \pm 0.3$ & $-122 \cdot 1$ & \\
\hline \multicolumn{6}{|c|}{ Tri- and Tetraalkylated Ethylenes } \\
\hline & 21 & $2.47 \times 10^{2}$ & $7.5 \pm 0.1$ & $-159 \pm 0.3$ & $2.14 \times 10^{-4}(\operatorname{ref} 12 \mathrm{a})$ \\
\hline & $2 m^{e}$ & $\leq 2.47 \times 10^{-1}$ & $(19.9 \pm 0.1)$ & $(-156 \pm 1)$ & \\
\hline & $2 n$ & $5.2 \times 10^{2}$ & & & $9.15 \times 10^{-4}($ ref $12 a)$ \\
\hline & 20 & 8.70 & $17.7 \pm 0.2$ & $-136 \pm 1$ & $3.05 \times 10^{-4}($ ref $12 \mathrm{a})$ \\
\hline & $2 p^{\prime}$ & $>5.62$ & $(8.0 \pm 0.2)$ & $(-188 \pm 1)$ & $3.42 \times 10^{-4}($ ref $12 b)$ \\
\hline \multicolumn{6}{|c|}{ Styrenes } \\
\hline & $2 q$ & $1.09 \times 10^{1}$ & $19.3 \pm 0.3$ & $-127 \pm 1$ & $2.40 \times 10^{-7}($ ref $12 a)$ \\
\hline & $2 \mathbf{r}$ & $1.45 \times 10^{3}$ & & & $9.67 \times 10^{-5}($ ref $12 \mathrm{c})$ \\
\hline & $2 s$ & 3.87 & $15.5 \pm 0.4$ & $-154 \pm 2$ & $1.12 \times 10^{-7}($ ref $12 \mathrm{~b})$ \\
\hline & $2 t$ & $8.29 \times 10^{-2}$ & $26.1 \pm 0.3$ & $-134 \pm 1$ & \\
\hline \multicolumn{6}{|c|}{ 1,3-Dienes } \\
\hline & $2 u$ & $1.93 \times 10^{-2}$ & & & $3.96 \times 10^{-8}($ ref $12 d)$ \\
\hline & $2 v$ & $4.62 \times 10^{1}$ & $22.4 \pm 0.3$ & $-99 \pm 2$ & \\
\hline & $2 w$ & $1.56 \times 10^{1}$ & $23.0 \pm 0.4$ & $-106 \pm 2$ & $3.19 \times 10^{-5}($ ref $12 \mathrm{~d})$ \\
\hline & $2 \mathbf{x}$ & $2.83 \times 10^{1}$ & & & \\
\hline & $2 y$ & $1.82 \times 10^{2}$ & $15.1 \pm 0.6$ & $-124 \pm 3$ & \\
\hline & 22 & $1.74 \times 10^{3}$ & & & $\sim 7.0 \times 10^{-78}$ \\
\hline & $2 \mathrm{aa}$ & $2.75 \times 10^{1}$ & $18.5 \pm 0.7$ & $-123 \pm 4$ & $\sim 7.0 \times 10^{-6}(\operatorname{ref} 12 \mathrm{a})$ \\
\hline 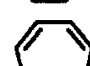 & $\mathbf{2 b b}$ & 3.04 & $22.1 \pm 0.8$ & $-123 \pm 4$ & $\sim 1.4 \times 10^{-8} 8$ \\
\hline
\end{tabular}




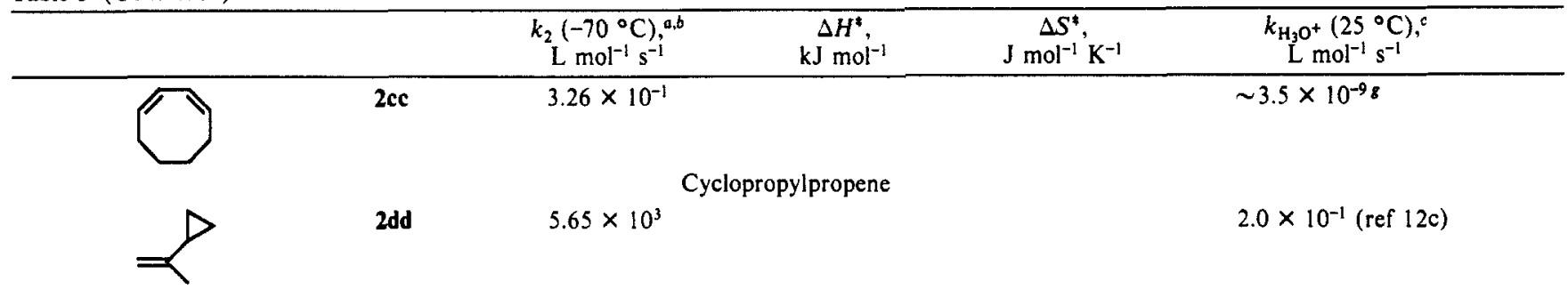

- Not corrected for statistical factors. ${ }^{b}$ If activation parameters have been determined, the $k_{2}$ values presented in this column are based on $\Delta H^{*}$ and $\Delta S^{*}$, which are given with more digits in the supplementary material. 'Rates of acid-catalyzed hydration. ${ }^{d}$ Data from ref $1 .{ }^{e} 2 \mathrm{~m}$ may isomerize into the more reactive $\mathbf{2 k}$. ${ }^{f}$ Addition step reversible, see text. 8 From $k$ (2aa) and the relative rate of hydration of this cycloalkadiene and 2 aa at 80 ${ }^{\circ} \mathrm{C}$; ref $12 \mathrm{e}$.

Table II. Effect of Methyl Groups at the Electrophilically Attacked Vinylic Carbon

\begin{tabular}{|c|c|c|c|c|}
\hline alkenes & & $\begin{array}{r}k_{\mathrm{CH}_{3}} / k_{\mathrm{H}} \\
\left(-70^{\circ} \mathrm{C}\right) \\
\end{array}$ & $\Delta H_{\mathrm{CH}_{3}}^{*}-\Delta H_{\mathrm{H}}^{*}$ & $\Delta S_{\mathrm{CH}_{3}}^{*}-\Delta S_{\mathrm{H}}^{*}$ \\
\hline & $2 \mathrm{~b} / 2 \mathrm{a}$ & 1.3 & -2.7 & -11 \\
\hline & $2 c / 2 a$ & 1.1 & -1.2 & -6 \\
\hline & $2 l / 2 f$ & 10.6 & -13.6 & -47 \\
\hline & $2 s / 2 q$ & 0.36 & -3.8 & -27 \\
\hline & $2 t / 2 q$ & 0.0076 & +6.8 & -7 \\
\hline & $2 y / 2 v$ & 3.9 & -7.3 & -25 \\
\hline
\end{tabular}

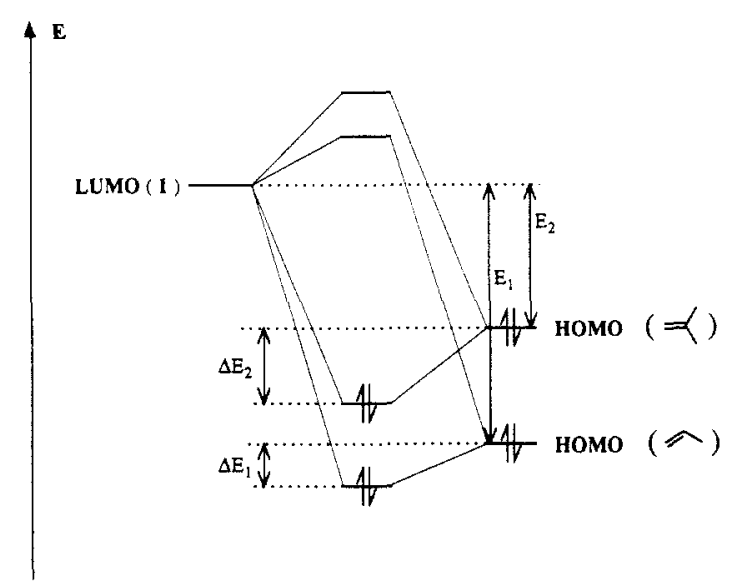

Figure 1. Frontier orbital interactions in reactions of alkenes with a carbenium ion.

is inversely proportional to the energy difference between the interacting orbitals $\left(E_{1}\right.$ and $\left.E_{2}\right)$, one can rationalize the increase of nucleophile reactivity with increasing height of the HOMO level $\left(E_{2}<E_{1} \rightarrow \Delta E_{2}>\Delta E_{1}\right)$. The inverse proportionality $\Delta E \sim 1 / E$ furthermore implies that the effect of a perturbation increases with decreasing magnitude of $E$, i.e., a perturbation of $E_{2}$ will affect $\Delta E_{2}$ to a greater extent than the same perturbation of $E_{1}$ will affect $\Delta E_{1}{ }^{15}$ Therefore, a greater reduction of $\Delta H^{*}$ is observed when a $\beta$-methyl group is introduced into isobutene (2f $\rightarrow 21)$ than into propene $(2 a \rightarrow 2 b, c)$. In accord with this interpretation, the accelerating effect of $\beta$-methyl groups increases as the energy of the carbenium LUMO is lowered; i.e. the activating effect of $\beta$-methyl groups grows with increasing reactivity of the reference carbenium ion. ${ }^{16}$

The higher reactivity of trimethylethylene (2l) compared with isobutene (2f) shows that the steric retardation by the additional

(15) (a) Fleming, I. Frontier Orbitals and Organic Chemical Reactions; Wiley-Interscience: London, 1976. (b) Giese, B. Angew. Chem. 1977, 89, 162; Angew. Chem., Int. Ed. Engl. 1977, 16, 125.

(16) Mayr, H.; Schneider, R.; Grabis, U., following paper in this issue.

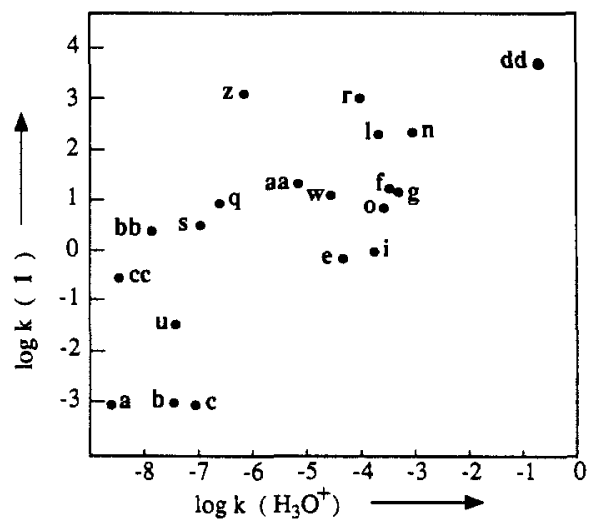

Figure 2. Correlation of the reactivities of alkenes and dienes 2 toward $\mathrm{H}_{3} \mathrm{O}^{+}\left(\mathrm{H}_{2} \mathrm{O}, 25^{\circ} \mathrm{C}\right)$ and the carbenium ion $1\left(\mathrm{CH}_{2} \mathrm{Cl}_{2},-70^{\circ} \mathrm{C}\right)$.

methyl group is overcompensated by its electronic acceleration. As expected, the steric effect outweighs the electronic effect in the case of tert-butyl, and $2 \mathrm{~m}$ is at least 2 orders of magnitude less reactive than isobutene. Since the degree of reversibility is not known for the reaction of 1 with $2 p,{ }^{11}$ the data given for $2 p$ cannot be discussed in structural terms.

1,3-Dienes. While the electrophilic attack at 1,3-butadiene (2u) generates a terminally monoalkylated allyl cation, all other dienes listed in Table I yield terminally dialkylated allyl cations. Since the stabilization of allyl cations predominantly depends on the number and not on the position of the terminal alkyl groups, ${ }^{17}$ the similar order of magnitude for the reactivities of the dienes $2 v-y$ can be explained. The decrease of $k_{2}$ with increase of ring size of the cycloalkadienes can qualitatively be attributed to the increase of deviation of the $\pi$-system from planarity. A more detailed analysis is given below.

\section{Transition-State Structure-Comparison with Proton Additions}

Comparison with Protonation Rates. Electrophilic additions toward alkenes may proceed through bridged or through open transition states. While bridged transition states are usually encountered in electrophilic brominations, chlorinations, and sulfenyl halide additions, ${ }^{18}$ proton additions are assumed to take place through open transition states. ${ }^{12,19}$ Ruasse, Dubois, and Argile have employed methyl effects to differentiate the two modes of attack: ${ }^{20}$ Whereas bridged transition states are stabilized by methyl groups at both vinylic termini, open transition states are

(17) Mayr, H.; Förner, W.; Schleyer, P. v. R. J. Am. Chem. Soc. 1979, 101,$6032 ; 1980,102,3663$ and references cited therein.

(18) Reviews: (a) de la Mare, P. B. D.; Bolton, R. Electrophilic Additions to Unsaturated Systems; Elsevier: Amsterdam, 1982. (b) Freeman, F. Chem. Rev. 1975, 75, 439. (c) Schmid, G. H.; Garratt, D. G. In The Chemistry of Functional Groups. Supplement A. The Chemistry of Double-Bonded Functional Groups; Patai, S., Ed.; Wiley-Interscience: London 1977; Part 2 , p 725. See also: (d) Collin, G.; Jahnke, U.; Just, G.; Lorenz, G.; Pritzkow, W.; Röllig, M.; Winguth, L.; Dietrich, P.; Döring, C.-E.; Hauthal, H. G.; Wiedenhöft, A. J. Prakt. Chem. 1969, 3il, 238.

(19) Nowlan, V. J;: Tidwell, T. T. Acc. Chem. Res. 1977, 10, 252.

(20) Ruasse, M. F.; Dubois, J. E.; Argile, A. J. Org. Chem. 1979, 44, 1173. 
Table III. Calculation of the Addition Enthalpy $\Delta H_{\text {add }}$ According to Scheme I and Equation 6

\begin{tabular}{|c|c|c|c|c|c|c|c|c|c|c|c|}
\hline adducts & & $\begin{array}{c}\Delta H_{\mathrm{a}} \\
\mathrm{kJ} \mathrm{mol}\end{array}$ & $10^{4} k_{\text {solv }}^{b}$ & 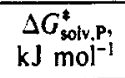 & $\begin{array}{c}\Delta H_{\text {add }}{ }^{c} \\
\mathrm{~kJ} \mathrm{~mol}^{-1}\end{array}$ & adducts & & $\begin{array}{c}\Delta H_{\mathrm{a}} \\
\mathrm{kJ} \mathrm{mol}^{-1 \mathrm{a}}\end{array}$ & $10^{4} k_{\text {solv }}^{b}$ & $\begin{array}{c}\Delta G_{\text {solv }, \mathrm{P}}^{*} \\
\mathrm{~kJ} \mathrm{~mol}^{-1}\end{array}$ & $\begin{array}{c}\Delta H_{\text {add }}{ }^{c} \\
\mathrm{~kJ} \mathrm{~mol}^{-1}\end{array}$ \\
\hline & $3 a$ & -105.7 & $\sim 1.4 \times 10^{-5 d}$ & 134 & -30 & & $3 \mathbf{n}$ & -92.6 & $\sim 1100^{\circ}$ & 85 & -72 \\
\hline & 3b & -96.5 & $\sim 1.4 \times 10^{-5 d}$ & 134 & -21 & & 30 & -85.3 & 6.3 & 99 & -49 \\
\hline & $3 c$ & -94.2 & $\sim 1.4 \times 10^{-5 d}$ & 134 & -19 & & & & & & \\
\hline & & & & & & & $3 p$ & -57.1 & 86 & 92 & -29 \\
\hline & 3d & -98.4 & $\sim 6.3 \times 10^{-3}$ & 118 & -41 & & & & & & \\
\hline & & & & & & & 39 & -90.8 & 0.058 & 112 & -41 \\
\hline & $3 e$ & -109.9 & $\sim 0.095^{e}$ & 110 & -61 & & $3 \mathbf{r}$ & -88.1 & $\sim 3500^{d}$ & 82 & -71 \\
\hline & $3 f$ & -97.0 & 0.77 & 105 & -55 & & $3 s$ & -79.8 & 0.083 & 111 & -31 \\
\hline & $3 g$ & -94.5 & 1.4 & 103 & -54 & & $3 t$ & -110.7 & 0.075 & 111 & -61 \\
\hline & $3 \mathbf{h}$ & -91.7 & 2.6 & 102 & -53 & & $3 \mathbf{u}$ & -72.5 & 0.064 & 111 & -23 \\
\hline & & & & & & & $3 v$ & -70.4 & $\sim 56$ & 93 & -41 \\
\hline & $3 \mathbf{i}$ & -87.6 & 6.1 & 99 & -51 & & $3 w$ & -75.2 & 1.2 & 104 & -34 \\
\hline & $3 \mathbf{j}$ & -95.0 & 1.5 & 103 & -55 & & $3 z$ & -84.7 & $\sim 9100^{\prime}$ & 80 & -70 \\
\hline & $3 \mathbf{k}$ & -79.0 & 29 & 95 & -48 & & $3 a a$ & -88.0 & 13 & 97 & -54 \\
\hline & $3 \mathbf{I}$ & -85.7 & 8.7 & 98 & -51 & & $\mathbf{3 b b}$ & -73.4 & $\sim 20^{\prime}$ & 96 & -41 \\
\hline & & & & & & & $3 \mathrm{cc}$ & -82.5 & $\sim 0.15 f$ & 109 & -35 \\
\hline
\end{tabular}

${ }^{a}$ From force field calculations; ${ }^{25}$ in all cases, the enthalpy of the most stable conformer of 3 has been used for the calculations. Experimental values for $\Delta H_{\mathrm{a}}: 3 \mathrm{j},-84.5 \pm 3.6 ; 3 \mathrm{l},-78.9 \pm 3.8 ; 3 \mathrm{q},-83.4 \pm 3.2 ; 3 \mathrm{~s},-78.1 \pm 4.4 ; 3 \mathrm{w},-74.2 \pm 2.9 \mathrm{~kJ} \mathrm{~mol}^{-1} ;$ ref 26 . ${ }^{b}$ Solvolysis rates of compounds $3 a-c c\left(R=\mathrm{Ph}_{2} \mathrm{CH}\right)$ in $80 \%$ ethanol at $50^{\circ} \mathrm{C}$; this work. These rates deviate only insignificantly from those of compounds with $\mathrm{R}=(p$ $\left.\mathrm{CH}_{3} \mathrm{OC}_{6} \mathrm{H}_{4}\right) \mathrm{PhCH}$; ref 1 . ' From eq 6 with $\Delta G_{\text {solv } \mathrm{R}}^{*}=67.1 \mathrm{~kJ} \mathrm{~mol}^{-1}$. This number is based on the solvolysis rate of AnPhCHCl $\left(50{ }^{\circ} \mathrm{C}, 80 \% \mathrm{EtOH}\right)$ $=97 \mathrm{~s}^{-1}$. which was derived from the activation parameters of the ethanolysis reaction of AnPhCHCl (ref 28) and the assumption that the LFER (ref 28 , Table 11 , entry 10$)$ also holds at $50^{\circ} \mathrm{C}$. ${ }^{d}$ Estimated from $k\left(3 \mathrm{f}, \mathrm{R}=\mathrm{Ph}_{2} \mathrm{CH}\right)$ and the relative ethanolysis rates $\left(25^{\circ} \mathrm{C}\right)$ of $3 \mathrm{f}(\mathrm{R}=\mathrm{H}, \equiv 1.0), 3 \mathrm{a}$ $\left(\mathrm{R}=\mathrm{H}, 1.8 \times 10^{-5}\right.$, also used for $\left.3 \mathrm{~b}, \mathrm{c}\right)$, and $3 \mathrm{r}(\mathrm{R}=\mathrm{H}, 4580)$ : ref 29 . 'Estimated from $k\left(3 \mathrm{o}, \mathrm{R}=\mathrm{Ph}_{2} \mathrm{CH}\right)$ and the relative ethanolysis rates $(25$ $\left.{ }^{\circ} \mathrm{C}\right)$ of $30(\mathrm{R}=\mathrm{H}, \equiv 1.0), 3 \mathrm{~d}\left(\mathrm{R}=\mathrm{H}, 1.0 \times 10^{-3}\right), 3 \mathrm{e}(\mathrm{R}=\mathrm{H}, 0.015)$, and $3 \mathrm{n}(\mathrm{R}=\mathrm{H}, 181)$, ref 29. ${ }^{f}$ Estimated from $k(3 \mathrm{aa}, \mathrm{R}=\mathrm{Ph}, \mathrm{CH})$ and the relative reactivities of the corresponding allyl bromides $(R=H)$ in $80 \%$ ethanol at $25^{\circ} \mathrm{C}$, ref 30 .

predominantly stabilized by methyl groups at the developing carbenium center. Melloni, Modena, and Tonellato have shown that alkenes are more reactive than alkynes in reactions involving bridged transition states, while analogously substituted alkenes and alkynes show similar reactivity toward nonbridging electrophiles. ${ }^{21}$ Both criteria led to the conclusion that carbenium ion additions are closely related to proton additions, though partial bridging in additions of diarylcarbenium ions toward $E, Z$-isomeric 2-butenes has been derived from stereochemical investigations.?

The data in Table I now allow a comprehensive comparison between proton and carbenium ion addition rates. Figure 2 shows that there is a moderate correlation between the two sets of data which refer to different temperatures. It is evident that conjugated $\pi$-systems (1,3-dienes and styrenes) react considerably faster with the carbenium ion 1 than expected from their reaction rates with protons. This deviation has to be seen in context with the previously reported, unexpectedly low reactivity of styrene toward protons. ${ }^{12 e}$ While in limiting $S_{N} 1$ solvolyses, the rate enhancement of a phenyl group is comparable to that of two methyl groups, ${ }^{22}$

(21) (a) Melloni, G.; Modena, G.; Tonellato, U. Acc. Chem. Res. 1981 14. 227. (b) Marcuzzi, F.; Melloni, G.; Modena, G. J. Org. Chem. 1979, 44, 3022 the acid-catalyzed hydration of styrene was found to be three orders of magnitude slower than the corresponding reaction of isobutene. Higher resonance stabilization of the ground state of styrene has been suggested to account for this reactivity difference. ${ }^{12 e}$ This explanation cannot be appropriate, however, since the heats of hydrogenation of isobutene and of styrene are identical within experimental error. ${ }^{23}$ As 1 attacks these two $\pi$-systems with similar rates (2f, 2 q, Table I), though the same ground-state effects must be encountered as in proton additions, an unknown transition-state effect must be responsible for the low reactivity of conjugated $\pi$-systems toward protons.

Rate equilibrium relationships can be employed for characterizing transition-state structures. ${ }^{24}$ As the rate-determining step of the reaction sequence under consideration corresponds to

(22) Streitwieser, A., Jr. Solvolytic Displacement Reactions; McGraw Hill: New York, 1962, p 43.

(23) Pedley, J. B.; Naylor, R. D.; Kirby, S. P. Thermochemical Data of Organic Compounds, 2nd ed.; Chapman and Hall: London, 1986.

(24) (a) Chapman, N. B.; Shorter, J. Advances in Linear Free Energy Relationships, Plenum Press: London, 1972. (b) Shorter, J. Correlation Analyses of Organic Reactivity; Research Studies Press (Wiley): Chichester, 1982. (c) Exner, O. Correlation Analyses of Chemical Data; Plenum Press: New York, 1988 


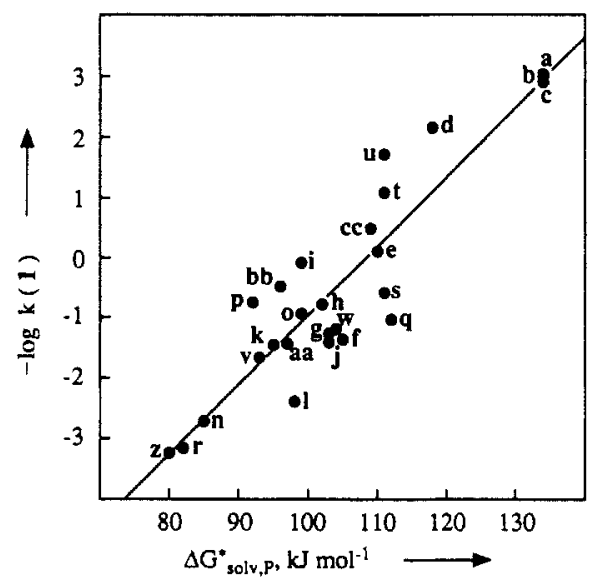

Figure 3. Correlation of the reactivities of alkenes and dienes 2 toward the carbenium ion $1\left(\mathrm{CH}_{2} \mathrm{Cl}_{2},-70^{\circ} \mathrm{C}\right)$ with the free energies of activation for ethanolysis of the adducts 3 .

Scheme I

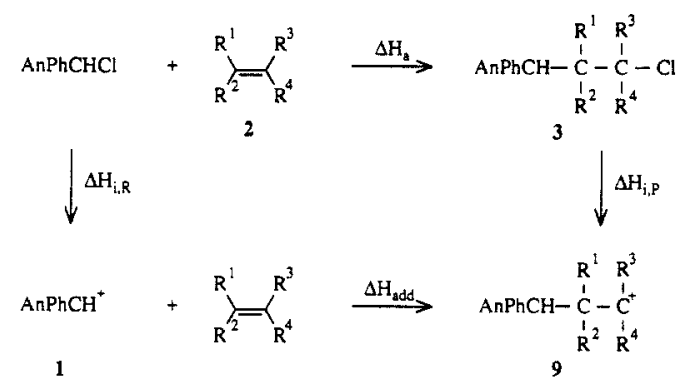

the attack of the carbenium ion 1 at the alkene 2 , the rate constants have to be compared with the free energy or the enthalpy of this step ( $\Delta H_{\text {add }}$ in Scheme I). According to Scheme I, $\Delta H_{\text {add }}$ can be calculated from a Hess cycle by using eq 5 . The enthalpies

$$
\Delta H_{\mathrm{add}}=\Delta H_{\mathrm{a}}+\left(\Delta H_{\mathrm{i}, \mathrm{p}}-\Delta H_{\mathrm{i}, \mathrm{R}}\right)
$$

$\Delta H_{\mathrm{a}}$, given in Table III, have been obtained by force field calculations. ${ }^{25}$ Comparison with some $\Delta H_{\mathrm{a}}$ values determined calorimetrically ${ }^{26}$ shows the typical errors of this computational method (see footnote $a$ of Table III). As the difference of the ionization enthalpies of reactants and products $\left(\Delta H_{\mathrm{i}, \mathrm{p}}-\Delta H_{\mathrm{i}, \mathrm{R}}\right)$

(25) PCMODEL, Molecular Modeling Software for the Macintosh II, Serena Software, Bloomington, IN, 1989. 567 . cannot be determined directly, this term has been replaced by $\left(\Delta G_{\text {solv, } \mathrm{P}}^{*}-\Delta G_{\text {solv, },}^{*}\right) / 0.89$ making use of the Arnett-Schleyer correlation. ${ }^{27}$ According to this correlation, $89 \%$ of the differences of the ionization enthalpies of alkyl chlorides in nonnucleophilic media are reflected by the differences of the activation free energies of the ethanolysis reactions. ${ }^{27}$ The correlation between the ad-

$$
\Delta H_{\mathrm{add}}=\Delta H_{\mathrm{a}}+\left(\Delta G_{\mathrm{solv}, \mathrm{P}}^{*}-\Delta G_{\mathrm{solv}, \mathrm{R}}^{*}\right) / 0.89
$$

dition rate constants $\left(\log k_{2}\right.$, Table I) and the addition enthalpies $\Delta H_{\text {add }}$ given in Table III is rather poor, however $(r=0.71)$, which is explained by the errors introduced by the force field calculations. This interpretation is supported by the observation that the free energies of activation for the ethanolysis of the products $\left(\Delta G_{\mathrm{solv}, \mathrm{P} \text {. }}^{*}\right.$ Table III) are fairly correlated with the corresponding addition rate constants ( $r=0.91$, Figure 3$)$. The existence of this correlation implies that $\Delta H_{\mathrm{a}}$, the term in eq 6 , which accounts for the different ground states of the $\pi$-systems, can be neglected, i.e., the reactivities of $\pi$-systems toward the electrophile 1 can roughly be estimated from the stabilization of the carbenium ions 9. Multiplication of the slope of the correlation in Figure 3 with $(-2.3 \times R T)$ yields a value of 0.45 , indicating that in the transition state roughly $50 \%$ of carbenium character is developed at the $\alpha$ carbon of the alkene.

\section{Conclusion}

The rate constants for the additions of 1 to the alkenes 2 roughly reflect the thermodynamics of the rate-determining step, in accord with a transition state, which is not strongly bridged. ${ }^{7}$ Though some analogy between the substituent effects on proton and carbenium ion additions is evident, diversities between the transition states of the two reaction series are indicated by the deviations from the correlation of Figure 2.

It remains to examine, whether the reactivity order measured for the carbenium ion 1 will also hold for other carbenium ions. For diarylcarbenium ions this question will be treated in the following paper.

Acknowledgment. We thank Ute Grabis for experimental assistance and the Deutsche Forschungsgemeinschaft and the Fonds der Chemischen Industrie for financial support.

Supplementary Material Available: Tables with concentrations and rate constants of the kinetic experiments described in Table I ( 8 pages). Ordering information is given on any current masthead page.

(27) Arnett, E. M.; Petro, C.; Schleyer, P. v. R. J. Am. Chem. Soc. 1979. $101,522$.

(28) Schade, C.: Mayr, H. Tetrahedron 1988, 44, 5761.

(29) Brown, H. C., Rei, M.-H. J. Am. Chem. Soc. 1964, 86, 5008.

(30) (a) Kiefer, E. F.; Roberts, J. D. J. Am. Chem. Soc. 1962, 84, 784.

(b) Schleyer, P. v. R.; Sliwinski, W. F., Unpublished results. 